\title{
Who Is the Note-Worthy Fan? Featuring Players in the Official Facebook Communication of Mainstream Video Games
}

Fans are an essential part of video game culture. As such, they also find their way into promotion of video games, either willingly or unknowingly. In the article we aim to enrich the current understanding of fan-producer relations by providing a quantitative overview of official Facebook communication of four mainstream video games (in chronological order): Dragon Age: Inquisition (BioWare, 2014), Evolve (Turtle Rock Studios, 2015), Mortal Kombat X (NetherRealm Studios, 2015) and The Witcher 3: Wild Hunt (CD Projekt Red, 2015). Using content analysis, we explore the frequency at which fans appear on official Facebook pages, what types of fans they are, and whether they are given credit for their creations. By combining these findings with the basic metrics of user activity collected by Netvizz (Rieder, 2013), we are also able to see if these communication strategies generate greater or lesser user activity than regular promotional posts.

Firstly, the appearance of players and fans and their creations in the official communication relates to a broader topic of participatory culture (Jenkins, 2006). The use of fan art or cosplay can be seen both as empowerment of fans (Milner, 2009) and as exploitation and free labor (Dijck \& Nieborg, 2009; Terranova, 2000). While we are not primarily interested in the users' perception of these practices, the approach to disclosing information about fan artists and giving them credit as authors of such artworks may be studied on a quantitative level and might show the producers' stance towards the authorship of fan creations. 
Secondly, the article deals with the question of gaming capital (Consalvo, 2007). However, we approach it from a very specific perspective of the professional communicators employed by video game companies who run the official Facebook profiles of video game franchises. Still, the selection of fans and fanworks on social media might show what developers and publishers understand as fan capital and, in consequence, which fans are note-worthy enough to be featured in the official communication.

Lastly, the article explores the question of ethics and fan privacy. Recently, Bennett, Chin and Jones (2016) have explored the questions of the use of fan works outside of their original contexts without permission, showing a growing interest of various stakeholders - from the general public to producers and journalists - in fan cultures and fanworks. Video game companies are no exception to this trend; they often organize fan contests and sometimes even feature fan art in games as unlockables and extras, for example in Mortal Kombat X. These acts of capitalization on fan activities are often concentrated around social media; fans are explicitly encouraged to share their content on sites like Facebook, Twitter and YouTube, which then serves as a promotional tool for a given cultural brand (Helens-Hart, 2014; Stork, 2014).

\section{Research Design and Methodology}

Based on previous, mostly theoretical or qualitative research, we have identified three aforementioned areas connected to the topic of fans in official promotion of video games. The issues of exploitation, fan capital (in this case, the cultural capital perceived by employees of video game companies), and ethics are explored through the following research questions.

- RQ 1: How prominently are fans and fanworks featured in official social media of video games compared to traditional promotional content?

- $\quad$ RQ 1.1: How much engagement is generated by posts featuring fans and by traditional promotional posts?

- RQ 2: What types of fans are featured in official social media profiles?

- $\quad$ RQ 2.1: Are there gender differences among fans and types of fans and their appearance in social media?

- RQ 3: How is the authorship offanworks treated in the context of social media through the practice of attribution and credit?

Empirical inquiry into producer-fan relations is currently lagging behind the ever-shifting practice, however, scholars have recently explored the questions of crowdfunding (Smith, 2015) and prosumption (Siuda, Troszynski, 2016) in the context of 
video game industry. The article aims to develop the understanding of these relations in the case of official promotion via social media sites. Due to the lack of previous quantitative research efforts, our design is mostly explorative and descriptive as it marks the first attempt to rigorously map the appearance of fans in the social media of the video game industry. Still, we believe that this design provides a necessary starting point for more detailed analyses into the role of fans in video game promotion not just as recipients but also as participants.

The aforementioned research questions serve as a basis for operationalization of five content variables - (V1) presence of a fan, (V2) gender of a fan, (V3) type of a fan, and (V4) forms of art if V4 is coded as an artist, and (V5) attribution to a fan.

The empirical material consists of all official posts from a one-year long period (August 1, 2014 to July 31, 2015) on the official Facebook profiles of four selected mainstream games: Dragon Age: Inquisition, Evolve, Mortal Kombat $X$ and The Witcher 3: Wild Hunt. The sample was constructed to contain different types of mainstream video games which were published during the analyzed time period, both primarily single-player (Dragon Age: Inquisition, The Witcher 3: Wild Hunt) and multiplayer (Evolve, Mortal Kombat X).

The whole population of 2,015 posts was collected using a data-mining tool $\mathrm{Ne}$ tvizz (Rieder, 2013). Following the data collection, we have conducted a two-step content analysis (Krippendorff, 2004a), which was carried out by the authors (two coders with equal distribution of coding units). The intercoder reliability was tested using a widely accepted index of Krippendorff's a (Feng, 2014; Krippendorff, 2004b; Lombard, Snyder-Duch, \& Bracken, 2002).

In the first step, we coded for presence of a fan (or a group of fans) in a Facebook post, taking into account its multimodal form (Norris \& Maier, 2014), including textual, visual and audiovisual information. This inquiry was operationalized using a binary variable (presence/absence) and first tested for intercoder reliability on a $10 \%$ sample (202 randomly selected units) with a score of 0.769 a which is deemed sufficient and reliable (Krippendorff, 2004b; Lombard et al., 2002). Our understanding of a fan is based on assumption that any player can be portrayed and understood as fan in the official communication except for the developers, publishers, and journalists who are presented in their official capacity.

Out of the whole population, 338 posts were identified as featuring fan(s) and these posts were subjected to the second round of content analysis. All following variables were first tested on a $14.8 \%$ sample (50 randomly selected units) for intercoder reliability using the index of $\alpha$ : gender of fans (four categories, $\alpha=1$ ), fan type (seven cate- 
gories, $\alpha=0.776$ ), art forms (seven categories, $\alpha=0.935$ ), credit (binary, $\alpha=1$ ). All the reliability scores were calculated using the ReCal web service (Freelon, 2010).

Apart from the content analysis, we were also using additional metrics collected by Netvizz, especially the overall measure of engagement which is a sum of all the following user activity: likes, comments, replies, shares, and comment likes (Rieder, 2013).

\section{Promoting Video Games on Facebook}

First of all, it is necessary to look at the specificities of the four social media profiles in question. Mortal Kombat as the video game series with the longest tradition (the first instalment was released in 1992) has the largest following among the sample, followed by the two established role-playing game franchises Dragon Age and The Witcher. The only new intellectual property, Evolve, has the lowest number of fans on Facebook (see Table 1). The official communication strategy also differs for the four games. Evolve has created the highest number of original posts, followed by Dragon Age and The Witcher. The administrators of Mortal Kombat Facebook profile were the least active in this regard (see Table 1).

\begin{tabular}{|l|r|r|}
\cline { 2 - 3 } \multicolumn{1}{c|}{} & Number of fans $^{*}$ & Number of posts \\
\hline Dragon Age: Inquisition & $1,325,000$ & 495 \\
\hline Evolve & 309,000 & 745 \\
\hline Mortal Kombat X & $5,718,000$ & 255 \\
\hline The Witcher 3 & $1,014,000$ & 520 \\
\hline
\end{tabular}

* Number of fans as of August 2015

Table 1 . Overview of social media activity

Looking at the user activity on the four sites, one can see a clear lead of Mortal Kombat with the total engagement nearing 5 million user interactions over the period of one year (see Table 2). Such a relatively high number compared to the other three games can be explained by the big fan following of Mortal Kombat which surpasses The Witcher and Dragon Age roughly five times. The lesser amount of posts also yields comparatively higher scores of the average (mean) engagement per one post. Note that Dragon Age and The Witcher have nearly identical scores in the measures of engagement and engagement per post suggesting that these two games have similarly active fan bases and also share a basic approach to social media communication regarding 
the volume of posts. Lastly, using the score of engagement per fan, we attempted to account for the different-sized fan communities on Facebook. Here, one can see that Evolve's fans are on average the most active with a score of 2.88 , meaning that on average one official fan of Evolve's Facebook official page interacts 2.88 times per one post by liking, sharing, commenting, replying to a comment, or liking a comment or a reply. The lowest score of Mortal Kombat can be to some extent explained by the time decay due to a large number of fans who might have not visited the Mortal Kombat Facebook page for a longer period of time. The attribute of time decay was considered to be one of the aspects determining the visibility of posts on Facebook in the era of EdgeRank (Bucher, 2012) and supposedly also influences the new News Feed algorithm (Rader \& Gray, 2015).

Visibility as well as sponsoring and promoting of posts might potentially influence engagement. Potential interpretations of user engagement data without the actual knowledge of the underlying algorithms and budgets spent on promoting certain posts are always limited. However, we would argue that all the games in question belong to a rather homogenous subset of video game industry and that their promotional strategies operate on a comparable scope. Under this assumption, we deem this basic descriptive overview of user activity relevant.

\begin{tabular}{|l|r|r|r|}
\cline { 2 - 4 } \multicolumn{1}{c|}{} & Engagement & $\begin{array}{c}\text { Engagement per } \\
\text { post }\end{array}$ & $\begin{array}{c}\text { Engagement per } \\
\text { fan }\end{array}$ \\
\hline $\begin{array}{l}\text { Dragon Age: } \\
\text { Inquisition }\end{array}$ & $2,353,809$ & $4,755.17$ & 1.78 \\
\hline Evolve & 891,435 & $1,196.56$ & 2.88 \\
\hline Mortal Kombat $X$ & $4,753,427$ & $18,640.89$ & 0.83 \\
\hline The Witcher 3 & $2,478,428$ & $4,766.21$ & 2.44 \\
\hline
\end{tabular}

Table 2. Overview of user activity

\section{Featuring Fans}

The initial round of content analysis showed that within the whole population of $\mathrm{Fa}$ cebook posts only $17 \%$ featured fans or fanworks (see Table 3). The highest frequency of "fan posts" was found on The Witcher's page, followed closely by Evolve. Both Dragon Age and Mortal Kombat showed a rather low amount of fan presence (8\%). This finding was rather surprising, especially in the case of Dragon Age, considering the regular weekly features of the so-called Fan Spotlight on Dragon Age social media and websites (see BioWare, 2015). This approach might signal a more systematic treatment 
of fan topics - fans themselves know when to expect fan-related content. They also get a secure and regular spot in the official communication and their fanworks are not used as a filler whenever there is not enough original promotional content.

Arguably, the information about the amount of "fan posts" provides only a very limited insight into the actual treatment of fans. Still, it serves as a testimony of the frequency of fan appearance or exploitation within promotional communication of video games on social media.

\begin{tabular}{|l|r|r|r|}
\cline { 2 - 4 } \multicolumn{1}{c|}{} & \multicolumn{1}{c|}{ Posts } & \multicolumn{1}{c|}{ Fan Posts } & Percentage \\
\hline $\begin{array}{l}\text { Dragon Age: } \\
\text { Inquisition }\end{array}$ & 495 & 38 & $8 \%$ \\
\hline Evolve & 745 & 154 & $21 \%$ \\
\hline Mortal Kombat X & 255 & 20 & $8 \%$ \\
\hline The Witcher 3 & 520 & 126 & $24 \%$ \\
\hline All & 2,015 & 338 & $17 \%$ \\
\hline
\end{tabular}

Table 3. Overview of fan posts

The next chart (see Chart 1) shows a chronological distribution of all the posts and the fan posts within the one-year period. The overall number of posts has a rising tendency ending in May 2015 when the last game of the sample (The Witcher 3: Wild Hunt) was released. The bigger activity preceding the launch of a video game is quite expected considering the cycles of video game production (Carlson, 2009). However, the relatively low numbers of fan posts in the release months of the individual games (November, February, April, and May, respectively) also suggest that in these stages of video game development, official content such as trailers (Švelch, 2015) is used for promotion instead of fans and fanworks. The highest number of posts featuring fans in August can be explained by the Gamescom video game trade fair which serves as an opportunity for cosplay and other fan activities. 


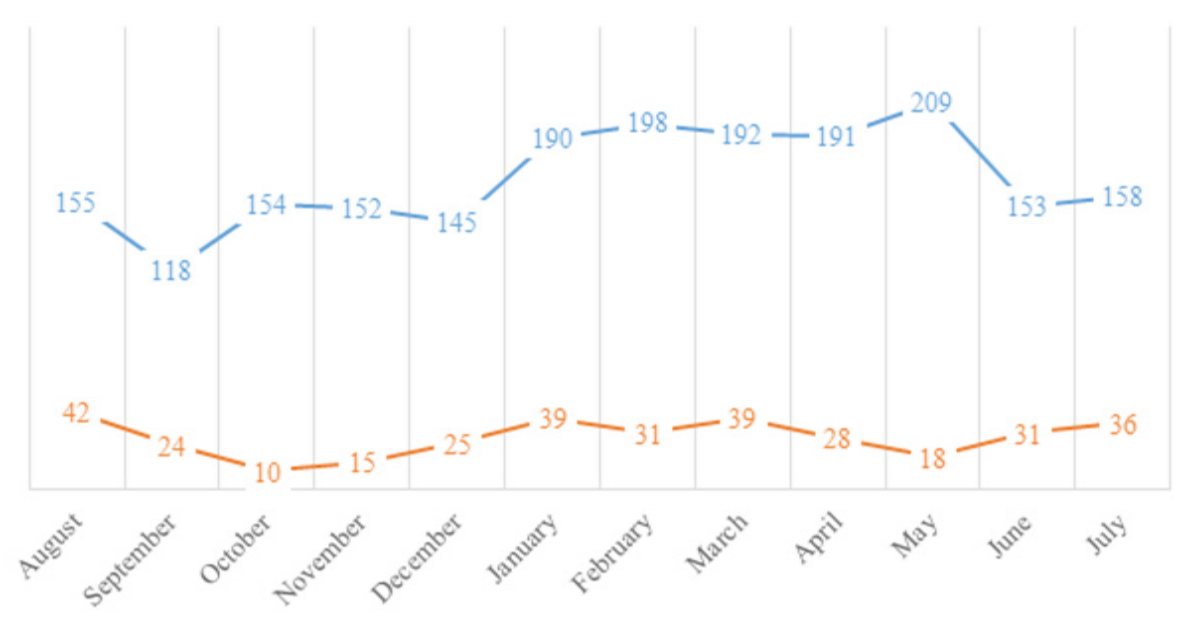

Chart 1. Chronological distribution of all posts (blue) and fan posts (orange)

\section{Fan Types}

In the second step of the content analysis, we have closely examined the types of fans that were featured in social media profiles. The typology of fans is based on our previous research on fan creations in official promotion of video games (Švelch \& Veselá, 2014) consisting of the following seven categories: (1) artist, (2) competitive player, (3) streamer/YouTuber, (4) celebrity, (5) conference attendee, (6) amateur walkthrough/guide/wiki maker, and (7) other.

The artist was the most frequently featured type of a fan on Facebook (57\%), followed by the competitive player (19\%) and the streamer/YouTuber (16\%); other categories were represented only marginally (see Table 4). Fan artists were dominant nearly across all the games while competitive players were understandably present only in multiplayer games Evolve and Mortal Kombat X. Streamers on Twitch and YouTube were often featured on Evolve's Facebook page during the alpha and beta versions of the game development. These findings suggest that the perceived fan capital among the administrators of social media profiles is first influenced by the overall visual culture of Facebook (boyd, 2011) and then by specificities of a given game which allow for emergence of a more traditional gaming capital, such as power gaming (Consalvo, 2007). 


\begin{tabular}{|c|c|c|c|c|c|c|}
\hline & Artist & $\begin{array}{l}\text { Competitive } \\
\text { Player }\end{array}$ & $\begin{array}{l}\text { Streamer/ } \\
\text { YouTuber }\end{array}$ & $\begin{array}{l}\text { Conference } \\
\text { Attendee }\end{array}$ & Celebrity & Other \\
\hline $\begin{array}{r}\text { Dragon Age: } \\
\text { Inquisition }\end{array}$ & 33 & 1 & 0 & 0 & 0 & 4 \\
\hline Evolve & 36 & 57 & 40 & 11 & 7 & 3 \\
\hline $\begin{array}{r}\text { Mortal } \\
\text { KombatX }\end{array}$ & 12 & 7 & 1 & 0 & 0 & 0 \\
\hline The Witcher 3 & 112 & 0 & 12 & 1 & 0 & 1 \\
\hline All & 193 & 65 & 53 & 12 & 7 & 8 \\
\hline
\end{tabular}

Table 4. Overview of types of featured fans $(n=338)$

\section{Forms of Art}

Considering the prominence of fan artists, we have also coded for specific forms of art (or fanworks) featured in social media profiles roughly. In this respect, we employ an arguably limited definition of art as a rather traditional assortment of literary and visual arts along the lines of what one can find on community websites such as DeviantArt. Other types of art are partly included in the previous distinction of fan types, e.g. streamers and streaming can be understood also as performance art. However, game-specific art of modding wasn't featured in any of the posts (according to our classification it would have been coded as other fan type).

We have constructed a basic typology of fan creations consisting of seven categories: (1) painting (including drawing and computer art), (2) sculpture (including statues, figurines, and replicas), (3) cosplay, (4) fan fiction, (5) music (including music videos with original music), (6) video, and (7) other. First of all, the complete absence of fan fiction, otherwise a very traditional form of fanwork (De Kosnik et al., 2015; Hellekson \& Busse, 2006), suggests that it is not perceived as a good promotional tool. On the other hand, the visual forms of fan art and cosplay seem suitable for Facebook and together account for 79\% of all featured fan creations (see Table 5). The arguably high number of items coded as "other" is again caused by Dragon Age Fan Spotlight posts which often consist of a variety of different fanworks including music and music videos, cosplay, and various types of sculpture. 


\begin{tabular}{|l|r|r|r|r|r|r|}
\cline { 2 - 7 } \multicolumn{1}{c|}{} & Painting & Cosplay & Music & $\begin{array}{l}\text { Statues/ } \\
\text { Replicas }\end{array}$ & Video & Other \\
\hline $\begin{array}{l}\text { Dragon Age: Inqu- } \\
\text { isition }\end{array}$ & 6 & 0 & 1 & 0 & 1 & 25 \\
\hline Evolve & 29 & 6 & 0 & 1 & 0 & 0 \\
\hline Mortal Kombat X & 10 & 2 & 0 & 0 & 0 & 0 \\
\hline The Witcher 3 & 52 & 47 & 6 & 6 & 1 & 0 \\
\hline All & 97 & 55 & 7 & 7 & 2 & 25 \\
\hline
\end{tabular}

Table 5. Overview of types of featured fan creations $(n=193)$

\section{Engagement}

A closer look at the average (mean) post engagement uncovers why fans are featured in social media in the first place. While "non-fan posts" generate the highest engagement on average (see Table 6), the subcategories of painting and cosplay surpass them in the number of likes and come close in the combined score of engagement. However, one should always be careful when interpreting user activity without information on post promotion, as we have already mentioned.

\begin{tabular}{|l|r|r|r|r|}
\cline { 2 - 5 } \multicolumn{1}{c|}{} & \multicolumn{1}{c|}{ Likes } & Comments & \multicolumn{1}{c|}{ Shares } & Engagement \\
\hline $\begin{array}{l}\text { Non-Fan } \\
(\mathrm{n}=1645)\end{array}$ & 3985 & 576 & 563 & 5752 \\
\hline Fan $(\mathrm{n}=338)$ & 2420 & 121 & 120 & 2854 \\
\hline Painting $(\mathrm{n}=97)$ & 4687 & 174 & 216 & 5481 \\
\hline Cosplay $(\mathrm{n}=55)$ & 4044 & 140 & 169 & 4652 \\
\hline
\end{tabular}

Table 6. Average (mean) Facebook user activity per post

\section{Gender}

We have coded for gender of featured fans distinguishing four categories: male, female, queer, and unspecified. Unlike other variables, we were also looking for additional information about gender of fans on their DeviantArt profiles if a link was included in the original post. First of all, there were no queer fans, such as crossplayers (Leng, 
2013). ${ }^{1}$ While male dominance (Shaw, 2010) was confirmed in the general category of fans $(67 \%, \mathrm{n}=141)$, among cosplayers women were the majority $(76 \%, \mathrm{n}=37)$. This discrepancy suggests that mainstream video game fandoms are still mostly male or at least perceived and portrayed in this way by social media administrators. Featuring women as cosplayers might be caused by two conflicting but not mutually exclusive tendencies of objectification of the female body within video game culture (Cassell \& Jenkins, 2000) and calls for a greater gender and sexual inclusion heralded by, among others, the developers of Dragon Age, namely by the former lead writer David Gaider (2013).

\section{Credit}

Lastly, we explored whether fan creations were attributed to particular fans or used as mere illustrations. Regarding the third research question of the treatment of fan authorship, 75\% out of total 338 "fan posts" were attributed to the original authors. This proportion applies to the whole sample, except for Dragon Age where it was exactly the opposite. Only $26 \%$ out of 38 posts which featured fans also credited them; however, this discrepancy was caused by the coding process. ${ }^{2}$ The posts about Fan Spotlight (26 in total) do not disclose information about fans on the social media page but they provide credit at the official website which hosts the whole article. Altogether, these findings suggest a respectful approach of social media teams towards fanworks and fans, whose ethos of sharing and intellectual property is based on attribution to original authors rather than the actual copyright law (Tushnet, 2007).

\section{Discussion}

The presented results allow us to think of a prototypical fan post used in the official promotion of video games. Firstly, it most likely features a fan artist, either a painter or a cosplayer. Secondly, such a fan is male unless it's a female cosplayer. Lastly, their work is credited, often with a link to their DeviantArt site or Tumblr blog. The rhetoric of featuring fans in social media seems simple in its aim of community building and brand management. Creativity of fans highlighted in Facebook posts serves as evidence to the popularity and positive reception of a given game. Featured fanworks are also used in motivating other players to participate actively in fandom and create their own art, and share it with video game companies.

1 Crossplay is a subversive variation on cosplay, however with switched genders, e.g. women cosplaying male characters.

2 Regarding the variable V3 (attribution to a fan), the coders took into account only the information available in a Facebook post. 


\section{Fan Exploitation}

All cases of fan posts can be easily interpreted as exploitation of fans by the official producers. Academic reflection on these complex fan-producer relationships has a strong tradition of such critical perspectives (Dijck \& Nieborg, 2009; Terranova, 2000). However, Milner has already argued against this protective position of critical theorists pointing to the autonomy of fans: "While scholars have altruistically wondered about the exploitation of fans by producers, Fallout fans would rather be financially exploited than have their immaterial labor ignored" (2009, p. 505)

Recently, Fast, Örnebring and Karlsson (2016) have attempted to provide an exhaustive overview of unpaid labor in the media sector. Their historically-grounded typology deals with potential motivations and the actual work tasks of actors performing free labor. Out of the seven proposed metaphors, the Hobbyist and the Apprentice relate the most closely to fan creations and their authors. The Hobbyist's reward "is affective: being paid in fun" (Fast et al., 2016, p. 9). However, some fans "take pride in developing their skills and dream of turning their hobby into a profession" (Dijck, 2009, p. 51), mirroring the motivations of the Apprentice. Emergence of fan-focused crowdfunding projects, for example the notorious fan porn creators Studio FOW (Hernandez, 2015), shows that video game fans can be easily understood as the Apprentices. ${ }^{3}$ However, their goal does not necessarily have to be employment within a video game company - fan projects can be sustained by financial support of other fans outside of the traditional economic structures thanks to platforms such as Patreon.

Considering the ethos of the so-called fannish gift economies (Booth, 2010; Hellekson, 2009) and the official communication, which often emphasizes the communal aspect of fandom, the metaphor of the Carer also applies to the topic of featuring fans in social media. In this context, Fast et al. explicitly mention that "[m]edia companies frequently attempt to leverage the community ties" (2016, p. 6) of fandom:

"Social networking sites rely on the creation and maintenance of affective ties in order to create value, and thus the active maintenance of social networks (e.g. through posting links and content, encouraging comments, or birthday greetings) could also be considered a type of free labor provided by Carers" (Ibid.)

However, we would argue that the call for community building and maintenance within creative fandoms surpasses the traditional activities connected to social media (liking, commenting, and sharing of official content) as it also encompasses creation

3 Still, media companies are able to capitalize on these fan aspirations by promising fan empowerment. For example, Fox offered interaction with the cast of the TV series Glee to the active members of the so-called Gleek community while generating buzz for the show in social media (Stork, 2014). 
and subsequent sharing of original fanworks. In consequence, these featured fanworks initiate another round of community building through subsequent discussion, dissemination and evaluation, as it was already pointed out by Helens-Hart (2014), who had explored the strategies of the TV series Tosh.0 aimed at motivating fan labor.

The often mentioned benefits of the convergence between fan and producer activities for the media industries (Dijck \& Nieborg, 2009; Fast et al., 2016; Helens-Hart, 2014; Stork, 2014) have to be to some extent pursued by producers in order to generate value. Recent exploration of Polish pop culture industry including the video games segment (Siuda, Troszynski, 2016) and our own results suggest that such interactions are in fact beneficial and are identified as such by video game producers.

\section{Perceived Fan Capital}

The issue of cultural capital ${ }^{4}$ is closely tied to the differences between particular types of fans in the context of social media promotion. However, we approach the underlying question of gaming capital ${ }^{5}$ (Consalvo, 2007) from a perspective of video game companies. In consequence, we do not deal with the gaming capital itself as a figurative currency of players within video game culture but as perceived gaming capital manifested in the official communication of video games. Still, such an inquiry can shed light on the shared understanding of gaming capital within mainstream video game culture. At the same time, the perceived cultural capital of a fan is potentially strengthened by their inclusion in the official promotion.

While examining differences between fan types, one should not overlook the hierarchical structures of fandom, whose members often distinguish between acceptable and merely tolerated fan activities, especially in relation to gender. Gaming culture has been repeatedly labeled as male-dominated and heteronormative (Cassell \& Jenkins, 2000; Mortensen, 2016; Shaw, 2010; Trammell, 2014), which also influences the notion of cultural capital. According to Busse, "affect and forms of fannish investment get policed along gender lines, so that obsessively collecting comic books or speaking Klingon is more acceptable within and outside of fandom than creating fan vids or cosplaying" (2013, p. 75) On the other hand, cosplaying fans have started attracting public attention and media coverage in recent years (Leng, 2013). While cosplayers

4 Castronova (2008) also identifies avatar capital in the context of video game culture.

5 For example, Consalvo (2007) has explored how expert knowledge about games contributes to the cultural capital of gamers, which is further established through gaming media and paratexts. In this perspective, skilled gamers such as professional e-sports competitors represent a privileged group within video game cultures. 
might be discriminated within the traditional fandom communities which follow patriarchal structures, our results prove that they might be valuable for video game publishers, especially in the context of visually-driven social media. As we have already mentioned, featuring cosplay - a traditionally less respected form of fan activity - might be motivated either by the heteronormative practice of objectification of the female body or the calls of greater inclusivity in fandom.

\section{The Ethics of Using Fan Cultures}

While video game producers attribute most of featured fanworks to their creators, it does not automatically mean that these creations are used with explicit permission from the fans. Bennett et al. (2016) have pointed to the risk fans undertake when they upload their creations on publicly accessible websites such as DeviantArt or Archive of Our Own. Fanworks are shared in specific contexts and fans often "perceive the space where they create their artworks as closed" (Busse \& Hellekson, 2012, p. 38), even though that is rarely the case. Therefore, it is understandable that fans sometimes try to protect their works by explicitly prohibiting any use without permission. ${ }^{6}$ However, the vague legal regulations of the fair use doctrine regarding derivative and transformative works (Schwabach, 2013) create paradoxical situations where the official producers might be in some cases entitled to such use of the fan creations as the rightful owners of the original intellectual property. ${ }^{7}$ According to Schwabach, currently "neither fans nor content owners truly understand the boundaries of fair use in fan works, [this situation] benefits neither" (2013, p. 92). In consequence, both fan artists and producers navigate a very tricky legal landscape, where the legal implications of their actions are difficult to understand and are largely dependent on good will and understanding from both sides of a potential conflict.

However, fan contests bypass the aforementioned grey zone by introducing legally binding contracts between contestants and video game publishers. For example, the Dragon Age: Fan Celebration Contest, which started in January 2015 and lasted until February 2015, was meant to "show our gratitude for our awesome community" according to the original copy (Dragon Age: Inquisition, 2015). The contest itself was promoted by other fan creations: "Throughout the contest, we will showcase several entries on Dragon Age social media sites to encourage creativity and inspire more fans

6 Authorial captions of fan creations also often contain disclaimers which acknowledge the copyright of the original owners of an intellectual property (see Tushnet, 2007).

7 This relates especially to fanworks that portray characters, objects or plot points which can be copyrighted as opposed to game mechanics (Lastowka, 2013). 
to participate." Ultimately, participation in such contests means giving nearly unlimited license to organizers allowing them to use submitted fanworks for promotional and marketing purposes:

“Uploading a Submission constitutes entrant's consent to give Sponsor a royalty-free, irrevocable, non-exclusive license to use, reproduce, modify, publish, create derivative works from, and display such submissions in whole or in part, on a worldwide basis, and to incorporate it into other works, in any form, media or technology now known or later developed, including for promotional or marketing purposes" (Dragon Age: Inquisition, 2015)

In the analyzed period, there were more fan contests organized for the selected games, including three separate events for The Witcher 3: Wild Hunt focusing separately on fan art, cosplay and screenshots. Evolve's social media team informally encouraged players to share their own content (Evolve, 2015). This way, producers get unconditional access to fanworks, which they can later use for promotion. In return, fans are offered greater visibility - potentially resulting in increased cultural capital and a chance to win special prizes, usually consisting of collector's editions of a game, brand merchandising, or gaming hardware. In very rare cases, talented fans are asked to become official employees of video game companies, further strengthening the narrative of a fan as the Apprentice (Fast et al., 2016). ${ }^{8}$

\section{Limitations}

The presented analysis has certain limitations resulting both from the choice of the material and the method of content analysis. Firstly, the sole focus on Facebook as the example of social media promotion might potentially misrepresent overall producer strategies relating fans and use of fanworks. Twitter, Tumblr and official websites also present relevant sites for research. This limitation has manifested especially in the case of Dragon Age: Inquisition which was promoting fan creativity on its own website in the so-called fan spotlights. The official Facebook page was often used just to bring attention to new fan-related content on the official website, working as a mere paratextual link (Švelch, 2016). Secondly, the limitations of the method are closely tied to the aforementioned case as the complex approach taken by BioWare eludes the coding instructions and makes Dragon Age: Inquisition an outlier, especially in the context of art type variable. Therefore, the lack of cosplay category in Table 5 does not necessarily

8 For example, Patryk Olejniczak won the Mass Effect fan art contest in 2011 and was offered a job of concept artist at BioWare, effectively gaining not only recognition among his fellow fans but also a chance to co-create the object of his fandom. 
mean that BioWare does not support such fan interactions, just that it presents them in different venues and combined with other types of fanworks. The content analysis also limits the interpretations of the three main topics - exploitation, gaming capital, and ethics - regarding the perspective of fans themselves as the material is connected to the producer side of these relations. Thus, we can only talk about, for example, perceived gaming capital of fans.

Future works might address the aforementioned limitations, for example the fan perception of such social media promotion. Other potential research topics might include the official communication strategies and guidelines (especially regarding cosplay and gender) for social media and also other sites such as Twitter, Tumblr or Instagram.

\section{Conclusion}

Addressing the titular question, we argue that a note-worthy video game fan in the context of social media promotion is a fan artist who either creates visual fanworks or engages in cosplay. Even though fans were only featured in $17 \%$ of all posts, attribution of their authorship and organization of various fan contests suggests a thought-out communication strategy which aims to motivate fans to provide content for video game promotion and marketing.

Fans and fanworks, especially fan art and cosplay, represent technically free content which is able to generate comparable user activity to regular promotional materials. From a perspective of developers and publishers, fan creations might be used in place of more costly official content and provide advantage to those who are willing to capitalize on fan creativity. For fans this potentially means a threat to their privacy or an increased chance of obtaining gaming (or fan) capital while pursuing certain forms of fan creativity.

\section{References}

Bennett, L., Chin, B., \& Jones, B. (2016). Between Ethics, Fandom and Social Media: New Trajectories that Challenge Media Producer/Fan Relations. In P. Booth \& A. Davisson (Eds.), Controversies in Digital Ethics (pp. 107-122). Bloomsbury Academic.

BioWare (2015). Dragon Age FanQuisition Spotlight - 6/30. Retrieved July 1, 2015, from http://www.dragonage.com/en_US/news/fanquisition-spotlight-jun-30

Booth, P. (2010). Digital fandom: new media studies. New York: Peter Lang. 
Boyd, D. (2011). Social Network Sites as Networked Publics: Affordances, Dynamics, and Implications. In Z. Papacharissi (Ed.), A networked self: identity, community and culture on social network sites (pp. 39-58). New York: Routledge.

Bucher, T. (2012). Want to be on the top? Algorithmic power and the threat of invisibility on Facebook. New Media \& Society, 14(7), 1164-1180. http://doi. org/10.1177/1461444812440159

Busse, K. (2013). Geek hierarchies, boundary policing, and the gendering of the good fan. Participations: Journal of Audience \& Reception Studies, 10(1), 73-91.

Busse, K., \& Hellekson, K. (2012), Identity, Ethics and Fan Privacy. In K. Larsen \& L. Zubernis (Eds.), Fan Culture: Theory/Practice (pp. 38-56). Cambridge Scholars Publishing.

Carlson, R. (2009). Too Human versus the enthusiast press: Video game journalists as mediators of commodity value. Transformative Works and Cultures, 2.

Cassell, J., \& Jenkins, H. (Eds.), (2000). From Barbie to Mortal Kombat: gender and computer games. Cambridge, Mass.: MIT Press.

Castronova, E., (2008). Synthetic Worlds: The Business and Culture of Online Games. University of Chicago Press.

Consalvo, M., (2007). Cheating: gaining advantage in videogames. Cambridge, Mass: MIT Press.

Dijck, J. van. (2009). Users like you? Theorizing agency in user-generated content. Media, Culture \& Society, 31(1), 41-58. http://doi.org/10.1177/0163443708098245

Dijck, J. van, \& Nieborg, D. (2009). Wikinomics and its discontents: a critical analysis of Web 2.0 business manifestos. New Media \& Society, 11(5), 855-874. http://doi. org/10.1177/1461444809105356

Dragon Age: Inquisition, (2015). Dragon Age: Fan Celebration Contest. Retrieved June 21, 2016, from https:/www.dragonage.com/en_US/news/fan-celebration-contest

Evolve. (2015). January 10, Evolve - Wanna share some Evolve content of your own? Maybe Ask... Retrieved June 21, 2016, from https://www.facebook.com/EvolveGame/posts/412997995525300:0

Fast, K., Örnebring, H., \& Karlsson, M. (2016). Metaphors of free labor: a typology of unpaid work in the media sector. Media, Culture \& Society. http://doi. org/10.1177/0163443716635861

Feng, G. C. (2014). Intercoder reliability indices: disuse, misuse, and abuse. Quality \& Quantity, 48(3), 1803-1815. http://doi.org/10.1007/s11135-013-9956-8

Freelon, D. G. (2010). ReCal: Intercoder Reliability Calculation as a Web Service. International Journal of Internet Science, 5(1), 20-33. 
Gaider, D. (2013). Video: Sexism and sexuality in games. Retrieved June 25, 2016, from http://www.gamasutra.com/view/news/194571/Video_Sexism_and_sexu

Helens-Hart, R. (2014) Promoting fan labor and "all things Web": A case study of Tosh.0. Transformative Works and Cultures, 2014(15).

Hellekson, K. (2009). A Fannish Field of Value: Online Fan Gift Culture. Cinema Journal, 48(4), 113-118. http://doi.org/10.1353/cj.0.0140

Hellekson, K., \& Busse, K. (2006). Fan Fiction and Fan Communities in the Age of the Internet: New Essays. McFarland.

Hernandez, P. (2015, March 11). The People Who Make Brutal Video Game Porn. Retrieved July 1, 2015, from http://kotaku.com/the-people-who-make-brutal-videogame-porn-1690892332

Jenkins, H. (2006). Fans, bloggers, and gamers: exploring participatory culture. New York: New York University Press.

Kosnik, A. De, El Ghaoui, L., Cuntz-Leng, V., Godbehere, A., Horbinski, A., Hutz, A., Pastel, R. \& Pham, V. (2015). Watching, creating, and archiving: Observations on the quantity and temporality of fannish productivity in online fan fiction archives. Convergence: The International Journal of Research into New Media Technologies, 21(1), 145-164. http://doi.org/10.1177/1354856514560313

Krippendorff, K. (2004). Content analysis: an introduction to its methodology (2nd ed). Thousand Oaks, Calif: Sage.

Krippendorff, K. (2004b). Reliability in Content Analysis: Some Common Misconceptions and Recommendations. Human Communication Research, 30(3), 411-433. http://doi.org/10.1111/j.1468-2958.2004.tb00738.x

Lastowka, G. (2013). Copyright Law and Video Games: A Brief History of an Interactive Medium (SSRN Scholarly Paper No. ID 2321424). Rochester, NY: Social Science Research Network.

Leng, R. H. Y. (2013). Gender, Sexuality, and Cosplay: A Case Study of Male-to-Female Crossplay. The Phoenix Papers, (First Edition), 89-110.

Lombard, M., Snyder-Duch, J., \& Bracken, C. C. (2002). Content Analysis in Mass Communication: Assessment and Reporting of Intercoder Reliability. Human Communication Research,28(4), 587-604. http://doi.org/10.1111/j.1468-2958.2002. tb00826.x

Milner, R. M. (2009). Working for the text: Fan labor and the New Organization. International Journal of Cultural Studies, 12(5), 491-508. http://doi. org/10.1177/1367877909337861 
Mortensen, T. E. (2016). Anger, Fear, and Games: The Long Event of \#GamerGate. Games and Culture. http://doi.org/10.1177/1555412016640408

Norris, S., \& Maier, C. D. (2014.) Interactions, Images and Texts, A Reader in Multimodality. Berlin, Boston: De Gruyter Mouton.

Rader, E., \& Gray, R. (2015). Understanding User Beliefs about Algorithmic Curation in the Facebook News Feed. In Proceedings of the 33rd Annual ACM Conference on Human Factors in Computing Systems (pp. 173-182). New York, NY, USA: ACM. http://doi.org/10.1145/2702123.2702174

Rieder, B. (2013). Studying Facebook via data extraction: the Netvizz application. In Proceedings of the 5th Annual ACM Web Science Conference (pp. 346-355). ACM.

Schwabach, A. (2013). Fan Fiction and Copyright: Outsider Works and Intellectual Property Protection. Ashgate Publishing, Ltd.

Shaw, A. (2010). What Is Video Game Culture? Cultural Studies and game studies. Games and Culture, 5(4), 403-424. http://doi.org/10.1177/1555412009360414

Siuda, P., \& Troszynski, M. (2016). Natives and tourists of prosumer capitalism: On the varied pro-prosumer activities of producers exemplified in the Polish pop culture industry. International Journal of Cultural Studies. https://doi. org/10.1177/1367877916666117

Smith, A. N. (2015). The backer-developer connection: Exploring crowdfunding's influence on video game production. New Media \& Society, 17(2), 198-214. https:// doi.org/10.1177/1461444814558910

Stork, M. (2014). The cultural economics of performance space: Negotiating fan, labor, and marketing practice in Glee's transmedia geography. Transformative Works and Cultures, 2014(15).

Švelch, J., \& Veselá, V. (2014). Fan Art in Official Promotion of Video Games. Presented at Fan Studies Network Conference 2014. Regent's University, London, UK, September 28, 2014.

Švelch, J. (2015). Towards a typology of video game trailers: Between the ludic and the cinematic. $G|A| M \mid E$, the Italian Journal of game studies, (4).

Švelch, J. (2016). "Footage Not Representative": Redefining Paratextuality for the Analysis of Official Communication in the Video Game Industry. In C. Duret \& C.-M. Pons (Eds.), Contemporary Research on Intertextuality in Video Games (pp. 297-315). IGI Global.

Terranova, T. (2000). Free Labor: Producing Culture for the Digital Economy. Social Text, 18(2 63), 33-58. http://doi.org/10.1215/01642472-18-2_63-33 
Trammell, A. (2014). Misogyny and the Female Body in Dungeons \& Dragons. Analog game studies, I(III).

Tushnet, R. (2007). Payment in Credit: Copyright Law and Subcultural Creativity. Law and Contemporary Problems, 70.

\section{Ludography}

BioWare (2014). Dragon Age: Inquisition [PC, PS3, PS4, Xbox 360, Xbox One]. Canada: EA.

CD Projekt RED (2015). The Witcher 3: Wild Hunt [PC, PS4, Xbox One]. Poland: CD Projekt.

NetherRealm Studios (2015). Mortal Kombat X [PC, PS3, PS4, Xbox 360, Xbox ONE, iOS, Android]. USA: Warner Bros. Interactive Entertainment.

Turtle Rock Studios (2015). Evolve [PC, PS4, Xbox One]. USA: 2K Games.

\section{Summary}

Video game fans participate in the official promotion of video games, either voluntarily, or unwillingly when their fanworks are appropriated and used by video game publishers. The article provides a quantitative overview of the presence of fans in the official social media profiles of four selected mainstream games (Dragon Age: Inquistion, Evolve, Mortal Kombat X and The Witcher 3: Wild Hunt) during a one-year period from August 2014 to July 2015. Combining the traditional method of content analysis and Facebook data-mining, we explore the frequency with which fans appear in social media (including questions of various forms of fanworks and gender) and what user activity is generated by posts featuring fans and fan creations. Results show that fans or their fanworks are featured in $8-24 \%$ of all posts depending on a game and in the most common categories of painting and cosplay they generate a comparable level of user engagement as traditional promotional posts.

Keywords: video game fans, Facebook, official communication of video games, fan capital, free labor, fan co-creation, content analysis, fan art, cosplay, e-sports

Jan Švelch is a Ph.D. candidate at Charles University. His research focuses on video game paratextuality, glitches, microtransactions, fan communities, and fan cultures. He works as a freelance journalist covering video games for various Czech magazines. 
Tereza Krobová is a Ph.D. candidate at Charles University. Her research focuses on issues related to gender and representation in media, especially in video games. She cooperates with NGOs that deal with human rights and gender mainstreaming. 